\title{
İstanbul ikitelli organize sanayi bölgesinde yer alan orman ürünleri sanayi işletmelerin finansman sorunları ve çözüm önerileri
}

\section{Financing problems and solution proposals of forest products industry enterprises in istanbul-ikitelli organized industrial zone}

\author{
Kadri Cemil AKYÜZ ${ }^{1}$ ibrahim YILDIRIM ${ }^{1}$ Osman HAMZAÇEBIOĞLU ${ }^{2}$ 'Dadir ERSEN ${ }^{3}$ \\ ${ }^{1}$ Orman Endüstri Mühendisliği Bölümü, Orman Fakültesi, Karadeniz Teknik Üniversitesi, Trabzon. \\ 2Orman Endüstri Yüksek Mühendisi, Elektronik Ar-Ge Departmanı, Rulopak Hijyen Sistemleri, İstanbul. \\ ${ }^{3}$ Ormancılık Bölümü, Artvin Meslek Yüksekokulu, Artvin Çoruh Üniversitesi, Artvin.
}

\section{Eser Bilgisi / Article Info}

Araştırma makalesi / Research article DOI: 10.17474/artvinofd.705450

Sorumlu yazar / Corresponding author Kadri Cemil AKYÜZ

e-mail: akyuz@ktu.edu.tr

Geliş tarihi / Received

18.03.2020

Düzeltme tarihi / Received in revised form

18.04.2020

Kabul Tarihi / Accepted

20.05.2020

Elektronik erişim / Online available 11.08.2020

\section{Anahtar kelimeler:}

Finansal Sorunlar

İstanbul

Orman Ürünleri Sanayi

\section{Keywords:}

Financial Problems

Istanbul

Forest Products Industry

\begin{abstract}
Özet
Firmaların sorunlarının önemli bir kısmı finansal alan kaynaklı olarak görülmekte ve diğer fonksiyonel yapılar üzerinde etkili olmaktadır. Bu çalışma orman ürünleri sanayi alanında üretim faaliyetinde bulunan firmaların finansal sorunları ve sorunlara yönelik belirledikleri çözüm önerilerinin tespit edilebilmesi amacıyla ülkemizin önemli sanayi bölgeleri arasında yer alan İstanbul ili íkitelli organize sanayi bölgesi genelinde gerçekleştirilmiştir. Tüm alt sektörleri kapsayıcı şekilde belirlenen 75 adet işletmede bilimsel geçerliliği kanıtlanmış anket formu ile şirket sahibi ya da yönetici konumda yer alan çalışanlarla görüşülerek işletmeler hakkında bilgiler alınmaya çalışılmıştır. Genel olarak firmaların finansman aracı olarak ticari banka kredilerini kullandıkları ve onların önemli bir kısmının sektörel destek amacıyla oluşturulan teşvik paketleri hakkında ve nasıl yararlanabilecekleri konusunda yeterli bilgi sahibi olmadıkları belirlenmiştir. Ayrıca banka faizlerinin yüksek olması, istedikleri zaman kredi kullanamamaları, bankaların çok yüksek oranlarda teminat istemeleri ve uzman personellerinin olmaması gibi sorunlar finansal problemleri arttırıcı bir nitelik taşımaktadır.
\end{abstract}

\begin{abstract}
Knowing the problems and searching for solutions is possible by strict monitoring of all market conditions. This study was carried out in ikitelli organized industrial zone of Istanbul which is one of the most important industrial zones of our country in order to determine the financial problems and solution proposals determined by the firms engaged in production in forest products industry. In 75 enterprises that were determined to cover all sub-sectors, a questionnaire with scientific validity was obtained and interviews were held with the employees of the company owners or managers to obtain information about the enterprises. As a result of the study, the main problems experienced by the enterprises in the financial field were determined and it was concluded that the desired quality of support was not obtained especially from public institutions and organizations. It has been determined that firms generally use commercial bank loans as a financing tool and a significant number of firms do not have sufficient information about the incentive packages created for sectoral support and how they can benefit from them. In addition, problems such as high bank rates, not being able to use loans whenever they want, banks' demanding collaterals at very high rates, and lack of specialist staff have an increasing nature of financial problems.
\end{abstract}

Giriş

Dünya genelinde meydana gelen sosyo-ekonomik değişimler, tüketim alışkanlıklarında oluşan farklılaşmalar, kaynaklar düzeyinde yaşanan azalmalar ve birçok farklı neden üretim birimlerini yeni arayışlara ve sahip oldukları pazar paylarını büyütebilme zorunluluğuna itmektedir. Ekonomilerin lokomotifi niteliğinde olan sanayi işletmeleri gelişme ve toplumsal kalkınmanın temel unsurunu oluşturmakta ve tüm alanlarda meydana gelen değişimlerden önemli oranda etkilenmektedir. Teknolojik yenilikleri yakalayabilme ve uygulama, değişen ve farklılaşan pazar koşullarına uyum, kalifiye işgücü temininde yaşanan zorluklar ve özellikle finansal piyasalarda oluşan hızlı ve takip edilebilmesi güç değişimler sanayi işletmeleri açısından sorunlar taşıdığı kadar farklı fırsat ve rekabet üstünlüklerini de beraberinde getirmektedir. Sıralanan bu değişim ve farklılaşmalar sanayi işletmelerinin sektörel ve ölçeksel 
büyüklükler temelinde farklı etkiler ve değerlendirmeler yapılmasını gerektirmektedir.

Ülkemiz imalat sanayi yapılanması içinde yer alan ve sahip olduğu istihdam ve üretim gücü nedeniyle önemli bir sektörel yapı niteliğinde olan Orman Ürünleri Sanayi Sektörünün finansman sorunlarının araştırılması ve çözüm önerilerinin sunulmasının amaçlandığı bu çalışma, ülkemizin finans, ekonomi ve üretim merkezi niteliğinde olan İstanbul ili-ikitelli organize sanayi bölgesinde genelinde faaliyet gösteren orman ürünleri sanayi işletmeleri düzeyinde gerçekleştirilmiştir. Ülkemizin birçok iline göre sahip olduğu kaynak ve farklı sektörel yapıların bir arada olması İstanbul ilinin seçiminde temel unsur olarak ön plana çıkmıştır. İçerisinde farklı alt sektörel yapılar ve ürün karmasında binlerce farklı ürün grubu bulunan orman ürünleri sanayi sektörünün ve araştırmanın yapılmış olduğu ikitelli organize sanayi bölgesinin önemli bir kısmını küçük ve orta ölçekli (KOBi) olarak tanımlanan işletmeler oluşmaktadır.

İçinde yer aldıkları ekonomik sistemin temel yapı taşı niteliğinde olan KOBi'ler, ekonominin barometresi konumunda bulunmakta ve ekonomik ortamın canlılığının göstergesi durumunda faaliyet göstermektedirler. Büyük işletmelerin faaliyet gösteremediği ya da pazar büyüklüğü nedeni ile yeterli görmedikleri küçük pazar alanlarında faaliyet gösteren KOBi'ler oluşan pazar boşluklarını doldurabilmekte ve farklılaşan tüketici ihtiyaçlarına karşı esnek bir üretim yapısı sergileyebilmektedirler. Büyük işletmelere önemli oranda girdi sağlayan KOBi'ler yan sanayi niteliği ile ekonomik yapıyı tamamlayıc özelliklere de sahip olmaktadırlar. Üretim gücü, sermaye bütünlüğü ve mülkiyetin tabana yayılmasında önemli görevler üstlenen KOBI'ler serbest rekabet, piyasa ekonomisi ve sosyal istikrarın temel unsurları niteliğindedir. Dünya ekonomisinde olduğu gibi Türkiye ekonomisinin de temel yapı taşı ve can damarları; küçük pazar boşluklarında faaliyet gösteren, tüketicilerin farklılaşan isteklerine cevap verebilen, istihdam oluşumu noktasında önemli görevler üstlenen ve gelişmiş gelişmemiş tüm bölgelerde faaliyet gösteren küçük ve orta ölçekli işletmelerdir (KOBi). Sahip oldukları önemli fonksiyonları yanında çözüm bulmaları gereken birçok sorunları da bulunan КOBi'ler içinde bulundukları ekonomik ve finansal sistemin güçlü ve ulaşılabilir olması koşulu ile ekonomik sisteme katkı sağlayabilecektir (Çelik ve Akgemici 1998, Müftüoğlu 2002, Erdoğmuş 2004, Torlak ve Uçkun 2005).

\section{Üretim Yapan Firmaların Sorunları}

Üretim yapan tüm firmalar bulundukları sektörel yapı ve genel ekonomik koşullara bağı olarak türlü sorunlarla mücadele etmek zorundadırlar. Nakit yönetimifinansman, pazarlama, personel temini ve sorunları, üretim ve hammadde sorunları, tedarik ve lojistik problemleri ve zamana göre şekillenebilen farklı sorunlar yönetici ve sahiplerin ilgilenmek ve çözüm bulmaları gereken konular arasında yer almaktadır.

Finansman sorunu günümüzde tüm işletmelerin çözüm bulmaları gereken bir konu niteliğinde olup farklı birçok problemin temelini oluşturmaktadır (Green 2003, Zengin

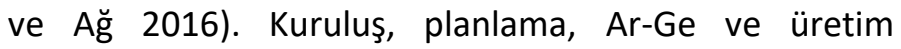
süreçlerinin tümünde farklı boyutlarda ortaya çıkan finansman sorunu, sahip olunan kaynakların etkin kullanılabilme becerisi ile yakından ilgili bir konumdadır. Finansal sorunlar genelinde kredi temininde yaşanan problemler, sermaye piyasasından fon sağlama sorunları, finansal yönetiminin eksiklikleri, öz sermaye ve işletme sermayesi sorunları olarak özetlenebilmektedir (Öndeş ve Güngör 2013). Ülkemiz piyasa koşullarında kendi öz sermayesi yeterli olan firmalar bile finansal alanda sorunlar yaşarken, yanlış ürün karması seçimi, finansal yapının etkin işletilememesi, teknolojik yapıda oluşan sorunlar ve kuruluş yeri problemleri gibi alt sorunlar finansal boyutta önemli etki derecesine sahip sorunları beraberinde getirmektedir.

Kaynak temin etmek firmaların sürekli ve planlı-plansız karşılaşmak durumunda olan bir konu niteliğindedir. Kaynak temininde temel kaynak bir çok firma için bankalar olurken, özellikle öz sermaye sahiplerinin güçlü yapıları ve etkin finans yöneticilerinin varlığı farklı alternatiflerin kullanılmasına imkan verebilmektedir. Bankalar özellikle belirli finansal yapı sahibi firmalara daha kolay kredi-kaynak temininde bulunurken özellikle yeterli teminat gösteremeyen firmalar bu imkanlardan yararlanamamaktadır. Ciroları belirli bir seviyenin üstünde olan firmalara hizmet verecek şekilde tasarlanan bankalar işletmelere kredi imkanı sağlarken işletmelerin 
mali durumlarına göre, teminat gösterip gösteremediklerine bakmaktadır. Teminat istenirken işletme içindeki makina ve teçhizat teminat kabul edilmemektedir. Kredi faizi oranlarının yüksek olması da kredi almalarını zorlaştırmaktadır.

Firmaların çoğunluğunda profesyonel anlamda finans bölümü ya da yöneticinin bulunmaması parasal işlemler, girdi-çıktı, kredi işlemleri, faiz oranları, parasal kaynaklar, teşvikler gibi sürekli olarak değişim gösteren ve takip edilmesi gereken konularda eksiklikler yaşanmaktadır. Firmaların önemli bir kısmında sermaye piyasasına açılmanın yarar getirmeyeceği aksine farklı maliyet unsurlarına neden olacağı kanısı hakim durumda bulunmakta ve bu durum farklı finansal kaynaklara ulaşımı engellemektedir. Kuruluş aşamasına intiyaç duyulacak sermaye yapısının ne düzeyde bir finans kaynak ihtiyacı oluşturacak olduğu ve bunun hangi kaynaklardan nasıl sağlanması gerektiği eksiklik ve sorun oluşturan bir başka konu niteliğindedir. İşletme kurulurken cepteki para işletme kurulumuna harcandığı için işletmenin belli bir süre kendini döndürebilmesi için gerekli sermaye ihtiyacı yok sayılmaktadır.

Işletme sahipleri aynı zamanda işletme yöneticileri olduğu için, sürekli gelişen teknoloji ve piyasa koşulları hakkında yeterli bilgi ve donanıma sahip olmaması, işletmede kalifiye veya bu işin uzmanı personellerin olmaması anlık kararlar vermede sorunlara yol açmaktadır. Hammadde teminindeki yetersizlikler ve düzenli bir üretim planının olmayışı dağıtımla ilgili sorunların ortaya çıkmasına neden olmaktadır. Bu gecikmeler üretimi sekteye uğratmakta ve teslim aşamasında gecikmelere yol açabilmektedir. Bu durum işletmeler için negatif yönde geri dönüş sağlamaktadır.

\section{MATERYAL VE YÖNTEM}

\section{Materyal}

Orman ürünleri sanayi alanında yer alan işletmelerin finansman sorunlarının belirlenmesinin amaçlandığı çalışma İstanbul ili, ikitelli organize sanayi bölgesinde yer alan orman ürünleri sanayi işletmeleri düzeyinde gerçekleştirilmiştir. Ikitelli organize sanayi bölgesinde orman ürünleri sanayi sektörünün farklı alanlarında faaliyet gösteren 350 adet işletme bulunmaktadır Çalışmada orman ürünleri sanayi sektörü içinde yer alan tüm alt sektörlerin yer alması planlanmış ve belirlenen örnek büyüklüğü bu doğrultuda gruplandırılmıştır.

\section{Yöntem}

Literatürde yer alan ve finansal sorunların belirlenmesine yönelik geçerliliği kanıtlanmış olan anket formu çalışma amacıyla kullanılmıştır (Akdağ 2014, Demir 2018). Veriler, hazırlanmış olan anket formu yardımıyla İstanbul ili ikitelli organize sanayi bölgesinde örneklem kapsamında belirlenmiş olan 75 adet işletmeye araştırmacı tarafından uygulanmıştır. Örnek büyüklüğünün belirlenmesinde aşağıda yer alan formülden yararlanılmıştır.

Çalışmada örnek hacmi hesaplanırken $\% 10$ hata payı ve \%95 güven düzeyinde örnek büyüklüğü;

$n=\frac{Z^{2} N P Q}{N D^{2}+Z^{2} P Q}$

formülünden yararlanılarak belirlenmiştir (Dorman ve ark. 1990). Burada;

n: Örnek büyüklüğü,

$Z^{2}$ : Güven katsayısı (\% 95'lik güven katsayısı 1.96 alınmıştır),

P: Ölçmek istediğimiz özelliğin evrende bulunma ihtimali (Çalışmamızın çok amaçlı olmasından dolayı bu oran \% 50 alınmıştır),

Q: 1-P ve

D: Kabul edilen örnekleme hatası \% 10 alınmıştır.

Yapılan hesaplamalar sonucunda; örnek büyüklüğü $n=75$ çalışan olarak tespit edilmiştir. Anketlerde kullanılan soruların bir kısmı kapalı uçlu soru, bir kısmı ise $5^{\prime}$ li Likert tipi sorulardan oluşmaktadır. Çalışma verileri SPSS 19 paket programı yardımı ile değerlendirilmiştir.

\section{BULGULAR VE TARTIŞMA}

İstanbul ikitelli organize sanayi bölgesinde yapılan anketler sonucunda firmalar hakkında elde edilen bilgiler Çizelge 1'de gösterilmektedir. Araştırma kapsamında yer alan işletmelerin alt sektörel düzeyde dağılımları incelendiğinde araştırma amacımıza uygun bir dağııımın elde edildiği görülmektedir (Çizelge 1). İşletmelerin 
$\% 60$ '।ık kesiminin 20 yıl ve daha az bir faaliyet yılına sahip olduğu görülürken, 41 yıl ve üzerinde faaliyet süresine sahip olan firma oranı \%10 düzeyindedir. Araştırma kapsamında yer alan işletmelerin yıllık kar düzeyleri incelendiğinde dikkat çekici bir şekilde 3 adet işletmenin zarar konumunda olduğunu belirtmesine karşın \%73 düzeyindeki işletme ise $50.001 \mathrm{TL}$ ve üzeri kar yapmış olduğunu belirtmiştir. Araştırma kapsamında yer alan firmaların \%60'ı 10 ve daha az işçi çalıştıran mikro ölçek boyutunda olmasına karşın işletme yöneticilerinin \%41'ı lisans ve daha üste bir eğitim seviyesine sahip düzeydedir. Araştırma kapsamında yer alan işletmelerin \%95' $\mathrm{i}$ üniversitelerle yeterli düzeyde bir iş birliği içinde olmadıkları, \%80'lik bir kesimde finans bölümü bulunmadığı belirlenmiştir. Araştırma kapsamında yer alan firmaların finansal araçları kullanma durumları hakkındaki bulgular Çizelge 2'de gösterilmiştir.

Çizelge 1: Firmalara ilişkin istatistiksel veriler

\begin{tabular}{|c|c|c|c|c|c|}
\hline Alt Sektör & $\mathbf{N}$ & $\%$ & Karlılık (TL) & $\mathbf{N}$ & $\%$ \\
\hline Tomruk-kereste imalatı ve satımı & 17 & 22 & $20.001-25.000$ & 2 & 2 \\
\hline Levha ürünleri imalatı ve satımı & 14 & 18 & $25.001-50.000$ & 15 & 20 \\
\hline Kapı, dolap imalatı ve satımı & 15 & 20 & 50.001 TL'den fazla & 55 & 73 \\
\hline Tamamlayıcı ürünler imalatı ve satımı & 10 & 8 & Zarar & 3 & 5 \\
\hline Mobilya, kaplama imalatı ve satımı & 14 & 18 & Toplam & 75 & 100 \\
\hline Diğer & 5 & 6 & Personel Sayıları & $\mathbf{N}$ & $\%$ \\
\hline Toplam & 75 & 100 & $<10$ çalışan & 45 & 60 \\
\hline Faaliyet Yılı & $\mathbf{N}$ & $\%$ & 11- 49 çalışan & 30 & 40 \\
\hline 10 yıldan az & 8 & 10 & Toplam & 75 & 100 \\
\hline $11-20$ yıl arası & 36 & 50 & Yönetici Eğitim Durumu & $\mathbf{N}$ & $\%$ \\
\hline $21-30$ yıl arası & 15 & 20 & İlkokul ve ortaokul & 20 & 26 \\
\hline $31-40$ yıl arası & 8 & 10 & Lise & 25 & 33 \\
\hline 41 yıldan fazla & 8 & 10 & Lisans ve üzeri & 30 & 41 \\
\hline Toplam & 75 & 100 & Toplam & 75 & 100 \\
\hline Finans Bölümünün Varlığı & $\mathbf{N}$ & $\%$ & Üniversite İşbirliği & $\mathbf{N}$ & $\%$ \\
\hline Var & 15 & 20 & Var & 4 & 5 \\
\hline Yok & 60 & 80 & Yok & 71 & 95 \\
\hline Toplam & 75 & 100 & Toplam & 75 & 100 \\
\hline
\end{tabular}

Çizelge 2: Iş̧letmelerin finansman araçlarını kullanma durumu

\begin{tabular}{|c|c|c|c|c|c|}
\hline \multirow[b]{2}{*}{ Ticari banka kredisi } & \multirow{2}{*}{$\begin{array}{l}\text { Hiç } \\
12\end{array}$} & \multicolumn{3}{|c|}{ Nadiren ArasıraSıksık } & \multirow{2}{*}{$\frac{\text { Sürekli }}{1}$} \\
\hline & & 16 & 18 & 28 & \\
\hline Yatırım bankası kredisi & 75 & 0 & 1 & 0 & 0 \\
\hline Eximbank kredisi & 75 & 0 & 1 & 0 & 0 \\
\hline Leasing & 73 & 0 & 2 & 0 & 0 \\
\hline Factoring & 45 & 5 & 15 & 10 & 0 \\
\hline Risk sermayesi & 75 & 2 & 1 & 0 & 0 \\
\hline Esnafa borçlanma & 75 & 0 & 0 & 0 & 0 \\
\hline Dış ülkelere borçlanma & 75 & 0 & 0 & 0 & 0 \\
\hline Vergi muafiyeti & 75 & 0 & 0 & 0 & 0 \\
\hline АВ КОВі destekleri & 75 & 0 & 0 & 0 & 0 \\
\hline Kredi Garanti Fonu & 70 & 0 & 0 & 5 & 0 \\
\hline Devlet destekleri & 70 & 2 & 3 & 0 & 0 \\
\hline Bankaların KOBi destekleri & 71 & 1 & 0 & 3 & 0 \\
\hline $\begin{array}{l}\text { KOSGEB, TÜBITAK, TTGV ve } \\
\text { EUREKA destekleri }\end{array}$ & 70 & 0 & 0 & 5 & 0 \\
\hline
\end{tabular}

İşletmelerin en yoğun olarak kullanmış oldukları finansman aracını ticari banka kredileri oluşturmaktadır (Çizelge 2). Araştırma kapsamında yer alan işletmeler Yatırım Bankası kredisi, Eximbank kredisi, risk sermayesi ve $A B, K O B i$ destekleri ile ilgili herhangi bir girişimde bulunmamış ve kullanma çabası içine girmemişlerdir. Bu kavramları ya da bu kurumların faaliyet alanları hakkında bilgileri ise oldukça sınırlı düzeydedir. Kullanma yoğunluğu bakımından Factoring ikinci sırada yer almakta ve işletmelerin finansman ihtiyacını karşılama bakımından etken konumda rol oynamaktadır. Işletmeler alacak haklarını devrederek finansman eksikliklerini tamamlamakta ve farklı finansman kurumlarına ihtiyaç duymamaktadırlar. İşletmelerin vergi muafiyeti konusunda herhangi bir girişimleri olmamış ve bu konuda bir istekte bulunmamışlardır. Araştırmada dikkat çeken bir diğer durum, az sayıda olmakla birlikte, işletmelerin kredi garanti fonu üzerinden kredi teminine girişmeleri ve bu konu hakkında bilgi sahibi olmalarıdır. Ayrıca Ar-Ge desteği niteliğinde olan ve hibe desteği sağlayan KOSGEB, TÜBITAK, TTGV ve EUREKA desteklerinin kullanım sıklığı az olmakla birlikte sanayicilerimiz tarafından kullanımda 
olması memnuniyet verici niteliktedir. Anket sonucunda önemli olan diğer bir durum ise özellikle esnafa borçlanma olarak tanımlanan finansman kaynağının hiç kullanılmamakta olduğudur. Yeşilkaya ve Çabuk (2018) çalışmasında Türkiye ahşap işleme makineleri imalat sektöründe faaliyet gösteren işletmelerin büyük çoğunluğunun KOSGEB ve özel finans kuruluşlarından dış finansman kaynağı kullandıklarını tespit etmiştir. Akdağ (2014), Demir (2018), Şahut (2019) ve Atalay (2019) KOBi'lerin dış finansman aracı olarak en fazla ticari banka kredilerini kullandığı ve alternatif finansman araçlarını ve teşvik / destekleri hiç veya çok az kullandığı sonuçlarına ulaşmışlardır.

İsletmelerin yoğun bir kullanım gösterdikleri banka kredilerine yönelik düşünceleri sorgulanmış ve elde edilen sonuçlar Çizelge 3'te gösterilmiştir (1: Kesinlikle katılmıyorum, 2: Katılmıyorum, 3: Kararsızım, 4: Katılıyorum, 5: Kesinlikle katılıyorum).

Çizelge 3: İşletmelerin kredi çeşit miktarlarının yeterliliği konusundaki düşünceleri

\begin{tabular}{llllll}
\hline & $\mathbf{1}$ & $\mathbf{2}$ & $\mathbf{3}$ & $\mathbf{4}$ & $\mathbf{5}$ \\
\hline Yeterli kredi çeşidi sağlanmamaktadır & 12 & 4 & 2 & 13 & 45 \\
Verilen kredi miktarı yetersizdir & 18 & 2 & 3 & 36 & 15 \\
Geri ödeme süreleri yetersizdir & 4 & 2 & 2 & 27 & 40 \\
\hline
\end{tabular}

Araştırma kapsamında elde edilen bulgular katılımcıların kredi çeşitliliği ve geri ödeme sürelerinin kısa olması nedeniyle sorunlar yaşadıklarını göstermektedir. Ancak Çizelge 2'de elde edilen veriler incelendiğinde aslında bu şikayetin tam anlamıyla doğru olmadığı ve bir çok finansal kredi ve kaynak türünden işletme sahiplerinin gerek bilgi eksikliği gerekse bürokratik sorunlar nedeni ile yeterince yararlanamadıkları anlaşılabilmektedir. Bu durumda asıl sorunun kredi eksikliği olmadığı bilgi ve bu alanda yardımcı kurum eksikliği olduğu görülmektedir.

İşletmelerin kredi bulmada yaşadıkları sorunlar ile yapılan çalışma sonucunda elde edilen bilgiler Çizelge 4'te gösterilmiştir (1: Kesinlikle katılmıyorum, 2: Katılmıyorum, 3: Kararsızım, 4: Katılıyorum, 5: Kesinlikle katıliyorum).
Çizelge 4: İşletmelerin kredi bulmada karşılaştıkları zorluklara ilişkin nedenler

\begin{tabular}{llllll}
\hline & $\mathbf{1}$ & $\mathbf{2}$ & $\mathbf{3}$ & $\mathbf{4}$ & $\mathbf{5}$ \\
\hline Teminat yetersizliği & 14 & 0 & 0 & 11 & 50 \\
Yüksek faiz oranları & 2 & 0 & 2 & 19 & 52 \\
Finansal tablo ve veri yetersizliği & 6 & 4 & 2 & 20 & 44 \\
\hline
\end{tabular}

Faiz oranlarının yüksekliği işletmelerin önemli kısmında şikayet konusu olarak gösterilmekle beraber, teminat konusunda yaşanan sıkıntılar diğer temel sorun niteliğindedir. Araştırma kapsamındaki işletmelerin KOBi niteliğinde olması ve bu nedenle finansal tabloların tutulmayışı ve muhasebe kayıtlarında oluşan sorunlar dikkate alınması gereken bir diğer sorunu oluşturmaktadır. Önceki çalışmalarda da (Yıldız ve Özolgun 2010, Kutlar ve Torun 2013, Akdağ 2014, Demir 2018, Atalay 2019) işletmelerin kredi alırken en fazla karşılaştıkları güçlükler yüksek faiz oranları ve teminat olduğu bulunmuştur. Bu da çalışma sonucu ile daha önceden yapılan çalışmalar arasında benzerliklerin olduğunu göstermektedir.

Araştırma kapsamında yer alan işletmelerin finansal kaynaklara intiyaç duyma nedenleri ile ilgili yapılan çalışma sonucunda elde edilen dağılım Çizelge 5'te gösterilmektedir (1: Kesinlikle katılmıyorum, 2: Katılmıyorum, 3: Kararsızım, 4: Katılıyorum, 5: Kesinlikle katiliyorum).

Çizelge 5: Finansman sorununun kaynağına ilişkin nedenler

\begin{tabular}{lccccc}
\hline & $\mathbf{1}$ & $\mathbf{2}$ & $\mathbf{3}$ & $\mathbf{4}$ & $\mathbf{5}$ \\
\hline Yatırımlardaki artışlar & 6 & 9 & 8 & 27 & 25 \\
Özkaynak yaratılamaması & 8 & 14 & 10 & 23 & 20 \\
Nakit para akışının sağlanamaması & 15 & 7 & 4 & 12 & 12 \\
Hammadde temini & 34 & 5 & 4 & 4 & 3 \\
İthal girdi kullanımı & 39 & 4 & 2 & 5 & 0 \\
Döviz sıkıntısı & 36 & 3 & 2 & 5 & 4 \\
Pazarlama ve dağıtım sorunları & 29 & 7 & 6 & 4 & 4 \\
Yüksek enflasyon ve makro ekonomik & 22 & 9 & 5 & 9 & 5 \\
etkenler & & & & & \\
\hline
\end{tabular}

Araştırma kapsamındaki firmaların finansal kaynak ihtiyacı temelde iki farklı nedenle oluşmaktadır. Bunlar; yatırım yapma isteği ve öz kaynak yetersizliğidir. Farklılaşan pazar koşullarına uyum sağlamak ve yeni üretim hatları oluşturmak isteyen firmalar oluşan, finansman intiyaçları hissetmektedirler. Bu durumun çözümü için büyük oranda banka kredisi talebinde bulunan firmalar ayrıca finansal kiralama yolunda tercih 
etmektedirler. Nakit dönüş sürecinde yaşanan sıkıntılar ve alacak temininin istenildiği boyutlarda yapılamaması finansman ihtiyacının oluşumunda etki sahibi olurken, piyasalarda oluşan dengesizlik ve nakit probleminin tüm sektörlerde oluşturduğu etki bu alanda da kendini göstermektedir. Akdağ (2014) KOBi'lerin daha çok nakit para akışının olmayışından kaynaklı finans sıkıntısı içerisinde olduğu sonucuna varmıştır. Kılıçlı ve Aygün (2018) KOBi'lerdeki finansman sıkıntılarını döviz kuru ve enflasyon oranları belirsizliği, gelir ve giderlerdeki sapmalar, yüksek maliyetler ve faiz oranları olarak sıralamaktadır. Başka bir çalışmada ise KOBi'lerin en fazla yüksek enflasyon ve ekonomik istikrarsızlıktan dolayı finansman sıkıntısı yaşadığını ifade etmiştir (Demir 2018).

Firmaların yaşanan finansman sorunlarına yönelik oluşturdukları çözüm önerileri öncelik sıralaması kapsamında Çizelge 6 'da gösterilmektedir.

Çizelge 6: Finansman sorunlarına çözüm önerileri

\begin{tabular}{llll}
\hline & $\mathbf{1}$ & $\mathbf{2}$ & $\mathbf{3}$ \\
\hline Uzun vadeli ve düşük faizli kredi & 70 & 3 & 2 \\
KOBi'lerin sermaye piyasasından yararlanması & 56 & 14 & 5 \\
için düzenlemeler & & & \\
KOBi'lerin gelişimi için yeni teşvikler & 66 & 7 \\
Teminat ve diğer formaliteler en aza indirilmesi & 63 & 5 & 7 \\
Bankalar dışındaki finans kurumlarından yararlanmak & 62 & 5 & 8 \\
\hline
\end{tabular}

Firmaların yüksek derecede önem verdikleri kredi kullanımı ve vade sorununun çözümü yaklaşımı beklenilen bir çözüm önerisi olmasına karşın özellikle KOBi'lerin sermaye piyasası yoluyla finansman intiyaçlarının giderilmesi önerisi dikkat çeken bir öneri niteliğindedir. Kredi temininde gerek bilgisel eksiklik ve gerekse teminat alanında yaşanan problemlerin azaltılması ve bu konularda firmaların desteklenmesi üretim devamlılığı için dikkate alınması gereken önemli, bir konu niteliğindedir. Bu çalışmada olduğu gibi Demir (2018) da finansman sorunların çözümü için ilk olarak uzun vadeli ve düşük faizli kredilerin sağlanması gerektiğini ifade etmiştir.

\section{SONUÇ VE ÖNERILER}

İstanbul ilinde orman ürünleri sektöründe faaliyet gösteren küçük ve orta ölçekli işletmelerin finansal yapı ve sorunları incelenmiştir. Bunun için 75 adet işletmeye yüz-yüze anket yöntemi uygulanmıştır.
Araştırma kapsamındaki işletmelerin büyük çoğunluğu 20 yıldan daha az üretim faaliyeti içerisinde yer almaktadır ve işletmelerin faaliyet gösterdikleri sektörler farklılık göstermektedir. Araştırma dahilindeki işletmelerin $\% 50$ 'sinden fazlası mikro ölçek düzeyinde olup, $\% 80$ 'inde finans uzmanı bulunmamaktadır. Finans işlemleri genellikle işletme sahipleri ve yöneticileri tarafından yapılmaktadır. Her ne kadar katılımcıların büyük çoğunluğu işletmelerinde ayrı bir finans departmanının olmadığını söylese de çalışmaya katılan işletmelerin çok az bir kısmının zarar ettiğini belirtmişlerdir. Üniversitelerden destek almayan işletmelerin oranı da oldukça yüksek düzeydedir.

Finansman sıkıntısı içerisinde olan işletmelerin bu sıkıntıdan kurtulmak için en fazla kullandığı finansman aracının ticari banka kredilerinin olduğu bulunmuş olup, bu kredilerinde düşük faizli ve yüksek vadeli olmalarını istemektedirler. Çalışma kapsamındaki işletmeler finansman araçlarına iki temel nedenden dolayı ihtiyaç duymaktadırlar. Bu iki temel neden ise yatırım yapma isteği ve öz kaynak yetersizliği olarak belirlenmiştir. Katılımcılar kredi çeşitliliğinin az ve geri ödeme sürelerinin kısa olmasından dolayı bu banka kredilerinde bir takım sorunlar yaşadıklarını söylemişlerdir. Ayrıca, çalışmaya katılan işletmeler faizlerin yüksek oluşundan ve teminat yetersizliğinden kaynaklı olarak kredi bulmada zorlandıklarını ifade etmişlerdir.

Sonuçları genel olarak özetleyecek olursak, küçük ve orta ölçekli işletmelerin finansal anlamda sorunların çözümü olarak algıladıkları temel unsur, banka kredileri, kredi miktarlarının boyutu ve geri ödeme faizi kapsamındadır. Bu bakış açısı var olan finansal sorunların çözümü noktasında kısıtlayıcı ve alternatifsiz bir duruma neden olmaktadır. Gerek yurt içi ve gerekse yurt dışı alternatif piyasalar hakkında yeterli bilgi sahibi olunmaması, bu alanlarda oluşabilecek yenilik ve farklılıklardan yararlanılamamasına neden olmaktadır. Bireysel olarak bir KOBi'nin yurt dışı piyasalara ulaşması ve finansal sorunlarını giderici çözümler araması gerçekçi bir yaklaşım olmayacaktır. Kurulacak birlikler ve oluşacak danışmanlıklar bu alanda sorun çözümüne katkı sağlayacaktır. Yurt dışı ve içi fuarlara katılım, Ar-Ge 
faaliyetlerinin çoğaltılması uzun ve kalıcı büyüme ve istikrarı sağlayacak temel unsurlar niteliğinde olacaktır.

\section{KAYNAKLAR}

Akdağ AO (2014) Kobilerin finansman sorunu ve çözüm önerileri Ankara ili uygulaması. Türk Hava Kurumu Üniversitesi Sosyal Bilimler Fakültesi Yüksek Lisans Tezi, Ankara.

Atalay E (2019) Kobilerin finansman sıkıntıları: Batman ili örneği. Batman Üniversitesi Sosyal Bilimler Enstitüsü Yüksek Lisans Tezi, Batman.

Çelik A, Akgemici T (1998) Girişimcilik kültürü ve KOBi’ler. Nobel Yayın Dağıtım, Ankara.

Demir R (2018) Turizm sektöründe kobilerin finansman sorunları ve çözüm önerileri: Şirince örneği. Adnan Menderes Üniversitesi Sosyal Bilimler Enstitüsü Yüksek Lisans Tezi, Aydın.

Dorman JS, LaPorte RE, Stone RA, Trucco, M (1990) Worldwide differences in the incidence of type I diabetes are associated with amino acid variation at position 57 of the HLA-DQ Beta Chain. Proc Natl Acad Sci U S A 87(19): 7370-7374.

Erdoğmuş N (2004) Aile işletmeleri: ikinci kuşağın yetiştirilmesi. İGiAD Yayınları, İstanbul.

Green A (2003) Credit guarantee schemes for small enterprises: an effective instrument to promote private sector-led growth?. Wilfried Lütkenhorst, Vienna.
Kılıçlı Y, Aygün M (2018) Kobilerin finansman sorunları ve çözüm önerileri: Van organize sanayi bölgesi üzerine bir inceleme. Vankulu Sosyal Araştırmalar Dergisi 1: 135-152.

Kutlar A, Torun P (2013) Diyarbakır'da faaliyet gösteren kobilerin profil yapısı karşılaştıkları sorunlara yönelik çözüm önerileri. Sakarya iktisat Dergisi 2(2): 27-42.

Müftüoğlu T (2002) Türkiye'de küçük ve orta ölçekli işletmeler. Turhan Kitabevi, Ankara.

Öndeş T, Güngör N (2013) KOBi'lerin finansmanı Erzurum organize sanayi bölgesinde bir araştırma. Atatürk Üniversitesi İktisadi ve İdari Bilimler Dergisi 27(1): 1-17.

Şahut $F$ (2019) Kobilerin finansman sorunları ve çözüm önerileri: Hatay örneği. Anadolu Üniversitesi Sosyal Bilimler Enstitüsü Yüksek Lisans Tezi, Eskişehir.

Torlak Ö, Uçkun N (2005) Eskişehir'deki Kobi'lerin pazarlama ve finansman sorunları ara kesiti. Sosyal Bilimler Dergisi 1: 199-215.

Yeşilkaya M, Çabuk Y (2018) Türkiye ahşap işleme makineleri imalat sektörünün finans ve pazarlama faaliyetlerinin analizi. Bartın Orman Fakültesi Dergisi 20(3): 558-564.

Yıldız F, Özolgun H (2010) İstanbul yöresi küçük ve orta ölçekli üretim işletmelerinin finansman fonksiyonu açısından değerlendirilmesi. Muhasebe ve Finansman Dergisi 48: 111-124.

Zengin Y, Ağ A (2016) KOBi'lerde başarıyı etkileyen finansman sorunu: neden mi? sonuç mu? literatür taraması sonucu bir değerlendirme. Akademik Bakış Dergisi 54: 227-241. 